\title{
Fibronectin and Its Receptors in Hematopoiesis
}

\author{
Franziska Wirth ${ }^{1}$, Alexander Lubosch ${ }^{1}$, Stefan Hamelmann ${ }^{1}$ and Inaam A. Nakchbandi ${ }^{1,2, *}$ \\ 1 Institute of Immunology, University of Heidelberg, 69120 Heidelberg, Germany; \\ franziska.wirth@immu.uni-heidelberg.de (F.W.); alexander.lubosch@immu.uni-heidelberg.de (A.L.); \\ stefan.hamelmann@immu.uni-heidelberg.de (S.H.) \\ 2 Max-Planck Institute for Medical Research, 69120 Heidelberg, Germany \\ * Correspondence: inaam.nakchbandi@immu.uni-heidelberg.de; Tel.: +49-622-156-8744
}

Received: 12 November 2020; Accepted: 15 December 2020; Published: 18 December 2020

\begin{abstract}
Fibronectin is a ubiquitous extracellular matrix protein that is produced by many cell types in the bone marrow and distributed throughout it. Cells of the stem cell niche produce the various isoforms of this protein. Fibronectin not only provides the cells a scaffold to bind to, but it also modulates their behavior by binding to receptors on the adjacent hematopoietic stem cells and stromal cells. These receptors, which include integrins such as $\alpha 4 \beta 1, \alpha 9 \beta 1, \alpha 4 \beta 7, \alpha 5 \beta 1, \alpha v \beta 3$, Toll-like receptor-4 (TLR-4), and CD44, are found on the hematopoietic stem cell. Because the knockout of fibronectin is lethal during embryonal development and because fibronectin is produced by almost all cell types in mammals, the study of its role in hematopoiesis is difficult. Nevertheless, strong and direct evidence exists for its stimulation of myelopoiesis and thrombopoiesis using in vivo models. Other reviewed effects can be deduced from the study of fibronectin receptors, which showed their activation modifies the behavior of hematopoietic stem cells. Erythropoiesis was only stimulated under hemolytic stress, and mostly late stages of lymphocytic differentiation were modulated. Because fibronectin is ubiquitously expressed, these interactions in health and disease need to be taken into account whenever any molecule is evaluated in hematopoiesis.
\end{abstract}

Keywords: fibronectin; hematopoiesis; integrin; adhesion; migration; homing; myelopoiesis; thrombopoiesis

\section{Introduction}

The bone marrow represents a unique environment optimized for hematopoiesis. On one hand, hematopoietic stem cells in the marrow need to be preserved throughout life, and on the other hand, they need to respond to acute changes in the requirement for various types of blood cells. They do this by answering cues from their surroundings, the neighboring cells, or distant organs. A variety of cells are located in close proximity of the stem cells, providing them with a protective environment, but also with short-distance signals to allow them to function. This niche was initially thought to be close to the bone lining cells or osteoblasts [1], but later work seems to localize the long-term hematopoietic stem cells in proximity to endothelial cells [2,3]. All these cells are embedded in a meshwork of extracellular matrix proteins produced by the supportive cells. This matrix modifies stem cell behavior by acting on receptors located on the surface of the stem cells and the supporting cells. Since matrix consists of a large number of molecules, and each affect different receptors, the matrix can exert a panoply of effects. Lastly, the matrix serves as a reservoir for growth factors changing their availability depending on its composition [4].

\section{The Rationale for Evaluating Fibronectin and Its Receptors}

Several extracellular matrix proteins have been examined in the context of hematopoiesis [5-7], but fibronectin stands out for a variety of reasons. It is produced by most mammalian cells. 
In the bone marrow, almost all cell types produce fibronectin, such as endothelial cells, pericytes, and osteoblasts [8-13]. Furthermore, circulating fibronectin infiltrates various tissues, including bone [14,15]. It can, therefore, be viewed as an integral component of the stem cell niche.

Fibronectin is a cell adhesion molecule. It consists of a heterodimer of two amino acid chains. These chains are composed of structural units lined up next to each other that can be classified into three types, type I, II, and III. Most units are similar between both chains, but three domains may differ: The extracellular domain A (EDA), the extracellular domain B (EDB), and the variable region (V). The isoform called plasma fibronectin lacks both EDA and EDB domains. While EDA or EDB can either be present or absent, the variable region can undergo alternative splicing [16]. Lastly, post-translational modifications further modulate the interaction of the molecule with the cells [17]. Fibronectin exerts a variety of functions by acting on cell surface receptors. It modulates proliferation, inhibits apoptosis, supports migration, and regulates differentiation $[9,11,12]$. It is, therefore, not surprising that fibronectin deletion during embryonic life is lethal [18]. Deletion in adult life using the Cre-LoxP system helped shed light on various postnatal roles [19]. This large variety of effects is possible through the presence of the various isoforms and post-translational modifications, as well as the large number of receptors to which fibronectin can bind.

\section{Fibronectin Receptors Relevant for Hematopoiesis}

Fibronectin mostly binds to integrins, which consist of heterodimers of an $\alpha$ and a $\beta$ subunit located on the cell surface. Integrins not only bind matrix and affect intracellular changes, but processes in the cell can themselves change the activation state of integrins, making them more likely to react to their surroundings [20]. Of the integrins able to bind fibronectin, five have been evaluated in hematopoiesis: $\alpha 5 \beta 1$ [21], $\alpha 4 \beta 1$ [22], $\alpha 4 \beta 7$ [23], $\alpha 9 \beta 1$ [24], and $\alpha \mathrm{v} \beta 3$ [25], all of which are expressed on hematopoietic stem cells (Table 1).

Table 1. Fibronectin can engage a large number of receptors-only receptors that were shown to be expressed on hematopoietic stem cells are listed.

\begin{tabular}{cc}
\hline Fibronectin Receptors Expressed on Hematopoietic Stem Cells \\
\hline \multirow{2}{*}{ Integrins } & $\alpha 5 \beta 1[21]$ \\
\cline { 2 - 2 } & $\alpha 4 \beta 1[22]$ \\
\cline { 2 - 2 } & $\alpha 4 \beta 7[23]$ \\
\hline TLR-4 & $\alpha 9 \beta 1[24]$ \\
\hline CD44 & $\alpha v \beta 3[25]$ \\
\hline
\end{tabular}

The classical fibronectin receptor is $\alpha 5 \beta 1$, which binds to the RGD (Arginine-Glycine-Aspartate) sequence in fibronectin. A site called connecting segment 1 (CS1) located in the variable region can bind $\alpha 4 \beta 1$ and $\alpha 4 \beta 7$ integrin. However, two more sites called H1 and CS5 offer binding sites to $\alpha 4 \beta 1$ integrin [16]. If CS1 is O-glycosylated at threonine 33, binding to $\alpha 4 \beta 1$ is affected by suppressing signaling through this integrin [17]. Interestingly, the presence of the EDA domain alters the characteristics of the binding to the classical fibronectin receptor $\alpha 5 \beta 1[19,29]$, but EDA has itself a binding site to two other integrins $\alpha 4 \beta 1$ and $\alpha 9 \beta 1$ [30,31]. A third integrin called $\alpha v \beta 3$ binds through the RGD sequence. This binding is modified by the presence of the EDB domain leading to increased intracellular response [32,33]. Close to the $\mathrm{N}$-terminal of fibronectin, a site was found that binds to $\alpha 5 \beta 1$ with low affinity and $\alpha \mathrm{v} \beta 3$ with high affinity [34]. Fibronectin can also engage other integrins that will not be mentioned here (reviewed in [16]). 
Three non-integrin receptors can bind to fibronectin. These are: Toll-like receptor-4 (TLR-4), CD44, and syndecan-4. Toll-like receptors (TLRs), including TLR-4 are expressed on hematopoietic stem cells [26,27], as is CD44 [28], but not syndecan-4.

Toll-like receptors are members of the receptors that recognize bacterial molecular patterns (also called pathogen-associated molecular patterns, PAMPs) located on immune cells, as well as other cell types. TLR-4 normally recognizes lipopolysaccharide (LPS) on gram-negative bacteria or lipoteichoic acid on gram-positive bacteria and induces the cells to produce cytokines, chemokines, and antibacterial/antiviral peptides. Both the EDA domain or the type III-1 domain can activate TLR-4 $[35,36]$. At first, it may seem surprising that fibronectin, which circulates in the bloodstream, would activate a proinflammatory receptor [37]. Most studies, however, used a fragment containing EDA or III-1 and not the whole molecule. It is, therefore, conceivable that the effect of EDA-containing fibronectin on TLR-4 is limited. Furthermore, fibronectin itself can be viewed as an opsonizer that facilitates phagocytosis of bacteria [32].

CD44 is considered a hyaluronic acid receptor, because it contains a hyaluronic acid-binding pouch. The binding affinity to hyaluronic acid, however, is affected by various post-translational modifications. The presence of chondroitin sulfate on one of the isoforms of CD44 allows it to bind fibronectin [38]. Of note, $\alpha 4 \beta 1$ and CD44 were found to cooperate to bind stromal cells to fibronectin [39].

Syndecan-4 is a proteoglycan that spans the cell membrane and can bind to fibronectin [40]. It modifies the expression of integrin pairs at the cell surface: If it is Src phosphorylated, it enhances $\alpha 5 \beta 1$ degradation and increases $\alpha v \beta 3$ [41]. It is not expressed on hematopoietic stem cells, but can be detected on monocytes and lymphocytes [42,43].

\section{Steps of Hematopoiesis}

During development, hematopoiesis starts early in the yolk sac, then moves to the liver and later to the bone marrow. This requires the migration of stem cells to the liver and then to the bone marrow. Once in the liver or the bone marrow, the stem cells need to initiate an interaction with the stromal cells and the matrix to be retained in the niche. Afterward, the stem cells may proliferate, giving rise either to a self-renewed stem cell or to a cell that starts differentiating to form the various blood cell types [44].

Once differentiation is initiated, the hematopoietic stem cell gives rise to the multipotent progenitor cells (MPPs). The stem cells and the multipotent progenitor cells together constitute the population characterized by the expression of c-Kit and Sca-1 in the absence of lineage markers for differentiated blood cells $\left(\mathrm{L}^{-} \mathrm{S}^{+} \mathrm{K}^{+}\right.$: Lineage-negative_Sca-1-positive_c-Kit-positive). These two groups are also known as the hematopoietic stem and progenitor cells (HSPC). For brevity in this review, the word stem cells refer to this HSPC population, since most papers did not characterize this population further or used variable sets of markers. The MPPs differentiate further to become either a common myeloid progenitor (CMP) or a common lymphoid progenitor (CLP). CMPs give rise to megakaryocyte-erythrocyte progenitors (MEPs) or granulocyte-monocyte progenitors (GMPs), while CLPs give rise to $B$ and T-cells. NK cells also originate from CLPs, while dendritic cells can originate from either CMPs or CLPs. Platelets and red blood cells originate from MEPs, while various monocytic population, macrophages, and granulocytes from GMPs and lymphocytes from CLPs [45].

\section{Fibronectin and Fibronectin Receptors in Hematopoietic Stem Cells}

Because fibronectin is ubiquitously expressed in the bone marrow, characterization of the specific effects of fibronectin on hematopoietic stem cells has proven difficult $[9,15,19,32]$. Most of our knowledge on how fibronectin affects hematopoiesis is deduced from what was learned by evaluating the role of the various receptors, because fibronectin was not directly examined together with each of the receptors mentioned above. Since, however, fibronectin is present in abundance and can bind to these receptors, it is likely that fibronectin acts via these receptors.

In the following, we present first the evidence of the role of integrins in hematopoiesis followed by a discussion of the effects of fibronectin and fibronectin-binding receptors on stem cell behavior: 
Migration and homing, attachment and retention, proliferation, and finally, differentiation. There is some overlap between these various steps, however.

\subsection{Evidence for A Role of Integrins in Hematopoiesis}

The role of integrins can be inferred from evaluating the effect of deletion of kindlin-3, a molecule required for integrin activation and signaling. Kindlin-3 is expressed in hematopoietic cells, and knockout cells were detected in the fetal liver, suggesting that homing to the fetal liver is not kindlin-3 dependent [46]. This, however, does not fully exclude a role for integrins, because enough functionality of the integrins might be maintained to support this step despite the loss of kindlin-3.

Homing to the bone marrow is markedly diminished, but not completely lost in kindlin-3 knockout mice, since homing and retention of stem cells in the bone marrow, at least in part, rely on CXCL12/SDF-1 $\alpha$ and its receptor CXCR4 [47,48]. Retention of quiescent cells was not affected in kindlin-3 knockout mice. Under stress conditions, however, homing to (and retention of) hematopoietic stem cells in the bone marrow requires the presence of functional integrins because kindlin-3 deletion depleted the hematopoietic stem cells [46]. A possible explanation is that signaling downstream of CXCR4/CXCL12 can activate integrins or that CXCL12 cooperates with integrins as was shown for homing and transmigration through the endothelium [21,49].

Dissecting the role of fibronectin in hematopoiesis is difficult, because of the presence of several fibronectin isoforms, each acting on different receptors. Adding to the complexity is that the receptors can have different effects depending on the developmental stage of the organism.

\subsection{Migration and Homing}

Fibronectin helps maintain the ability of the stem cells to reconstitute the bone marrow and supports engraftment [50]. This is mediated by fibronectin-binding to $\alpha 5 \beta 1$ integrin, possibly in cooperation with $\alpha 4 \beta 1$ and CD44 (Table 2).

Loss of $\beta 1$ integrin in hematopoietic stem cells prevents migration to the fetal liver or engraftment in the bone marrow of irradiated recipient adult mice. This underscores the importance of $\beta 1$ integrins in homing. In comparison, even though CXCL12/SDF-1 is a strong chemoattractant of hematopoietic stem cells and an important molecule for migration of stem cells to the bone marrow, deletion of its receptor markedly diminishes, but does not fully abrogate engraftment of hematopoietic stem cells in adult mice $[47,51]$.

Of the integrins that require $\beta 1$ subunit, the fibronectin receptor $\alpha 5 \beta 1$ supports the homing of progenitor cells to the bone marrow, as evidenced by decreased homing with the use of an inhibitory antibody [21]. $\alpha 4$ is another $\alpha$ subunit that pairs with $\beta 1$. Using chimeric mice (in which stem cells from knockout mice are transplanted into wildtype mice), it was determined that $\alpha 4$ is not required during embryonic development for migration of hematopoietic progenitors [52]. In adult mice, the use of inhibitory antibodies against $\alpha 4 \beta 1$ or knockout of $\alpha 4$ suggested $\alpha 4$ is essential for homing to the bone marrow after irradiation and transplantation [53-55].

In human hematopoietic stem cells, an isoform of CD44 called HCELL (Hematopoietic Cell E-/L-selectin Ligand) is detected [38]. Its expression in human stromal cells led to homing to the bone marrow, even though CXCR4 was not expressed in these cells [56]. This isoform, however, is only found on human hematopoietic stem cells and not on murine stem cells. In mice, CD44 also supports homing of hematopoietic stem cells [28]. Since the engagement of CD44 activates $\alpha 4 \beta 1$, allows binding to fibronectin [39], and triggers cell movement in the absence of chemokines [38], it is possible that through the cooperation of CD44/ $\alpha 4 \beta 1$ signaling on stem cells, their anchoring on mesenchymal stromal cells in the hematopoietic niche is enhanced. 
Table 2. Fibronectin supports hematopoietic stem cells in migration and homing, retention, and proliferation by acting on various receptors. Evidence for fibronectin involvement was established in vitro. Because fibronectin deletion in mice leads to embryonal death, the role of fibronectin in these steps in vivo was implied by evaluating the various receptors as outlined.

\begin{tabular}{|c|c|c|}
\hline $\begin{array}{c}\text { Function of Hematopoietic } \\
\text { Stem Cell }\end{array}$ & Role of Fibronectin & Role of Fibronectin Receptors \\
\hline \multirow{3}{*}{ Migration and homing } & \multirow{3}{*}{$\begin{array}{l}\text { Fibronectin acts in vitro to maintain } \\
\text { the ability of stem cells to engraft [50] }\end{array}$} & $\begin{array}{l}\text { Migration diminishes if } \beta 1 \text { is deleted } \\
\text { in hematopoietic cells }[47,51]\end{array}$ \\
\hline & & $\begin{array}{c}\alpha 4 \beta 1 \text { and } \alpha 5 \beta 1 \text { are required for } \\
\text { homing in adults [21,53-55] }\end{array}$ \\
\hline & & CD44 supports homing $[28,56]$ \\
\hline \multirow{3}{*}{ Retention } & \multirow{3}{*}{$\begin{array}{l}\text { Fibronectin supports attachment } \\
\text { in vitro [57] }\end{array}$} & $\begin{array}{l}\alpha 4 \beta 1 \text { enhances retention through } \\
\text { actions on stromal cells }[55,58]\end{array}$ \\
\hline & & $\begin{array}{l}\alpha v \beta 3 \text { maintains long-term } \\
\text { repopulation capacity, requires } \\
\text { thrombopoietin [25] }\end{array}$ \\
\hline & & $\begin{array}{l}\text { CD44 stimulates adhesion. Possible } \\
\text { cooperation with } \alpha 4 \beta 1 \text { [38] }\end{array}$ \\
\hline \multirow{3}{*}{ Proliferation } & \multirow{3}{*}{$\begin{array}{l}\text { Fibronectin stimulates cell } \\
\text { proliferation [9] }\end{array}$} & $\begin{array}{c}\alpha \mathrm{v} \beta 3 \text { engagement suppresses } \\
\text { proliferation }[25,59]\end{array}$ \\
\hline & & $\begin{array}{l}\text { TLR-4 activation with LPS increases } \\
\text { proliferation [60] }\end{array}$ \\
\hline & & CD44 inhibits proliferation [28] \\
\hline
\end{tabular}

\subsection{Attachment and Retention}

The stem cells are retained in the niche by adhering to stromal cells or to the matrix in the niche. If adherence is lost, the cells egress from the bone marrow and/or differentiate. Inhibiting the engagement of stem cells with their surrounding diminished the expression of stem cells-associated transcription factors cMyb and GATA-2 at the expense of increased expression of markers of differentiation [61]. This is compatible with the notion that the niche modifies the behavior of the stem cells depending on its composition.

The ability of fibronectin to support hematopoietic stem cell attachment is so well established that it is used in assays analyzing adhesion of hematopoietic stem and progenitor cells in vitro [57]. The ability of stem cells to engraft in vivo is markedly improved if stromal cells are provided [62]. Since adding fibronectin has the same effect [63], it could be that stromal cells provide fibronectin for the stem cells to tether to it (Figure 1).

In vivo studies thoroughly evaluated the retention of stem cells in the niche. Neither deletion of $\beta 1$ integrin in hematopoietic cells in the bone marrow in transplanted, and hence, chimeric adult mice, nor combined deletion of $\beta 1$ and $\beta 7$ in chimeric mice affected retention of hematopoietic stem cells in the bone marrow durably [23]. The application of antibodies against $\alpha 4 \beta 1$ integrin, however, mobilized stem/progenitor cells out of the niche, suggesting that $\alpha 4 \beta 1$ integrin contributes to the retention of the stem cells in the niche. In line with this, induced deletion of $\alpha 4$ in hematopoietic and several other cell types using Mx to drive Cre recombinase expression in floxed mice increased the release of progenitors into the peripheral blood [55].

The seemingly contradictory findings between $\beta 1$ deletion and $\alpha 4 \beta 1$ modulation can be explained as follows: The experiments in which $\beta 1$ and $\beta 7$ chimera were produced affect the hematopoietic stem cells themselves [23,64], while the experiments with the $\alpha 4$ antibody and $\alpha 4$ deletion using Mx-Cre inhibit or diminish $\alpha 4$ on the stem cells and on cellular components of the niche unrelated to hematopoietic cells $[55,58]$. The various results, therefore, support the conclusion that deletion of $\alpha 4$ in surrounding cells changes their ability to support hematopoietic stem cells and prevent them from 
retaining the hematopoietic stem cells in the bone marrow, while $\alpha 4$ in the hematopoietic stem cells plays a limited role in their retention in the bone marrow.

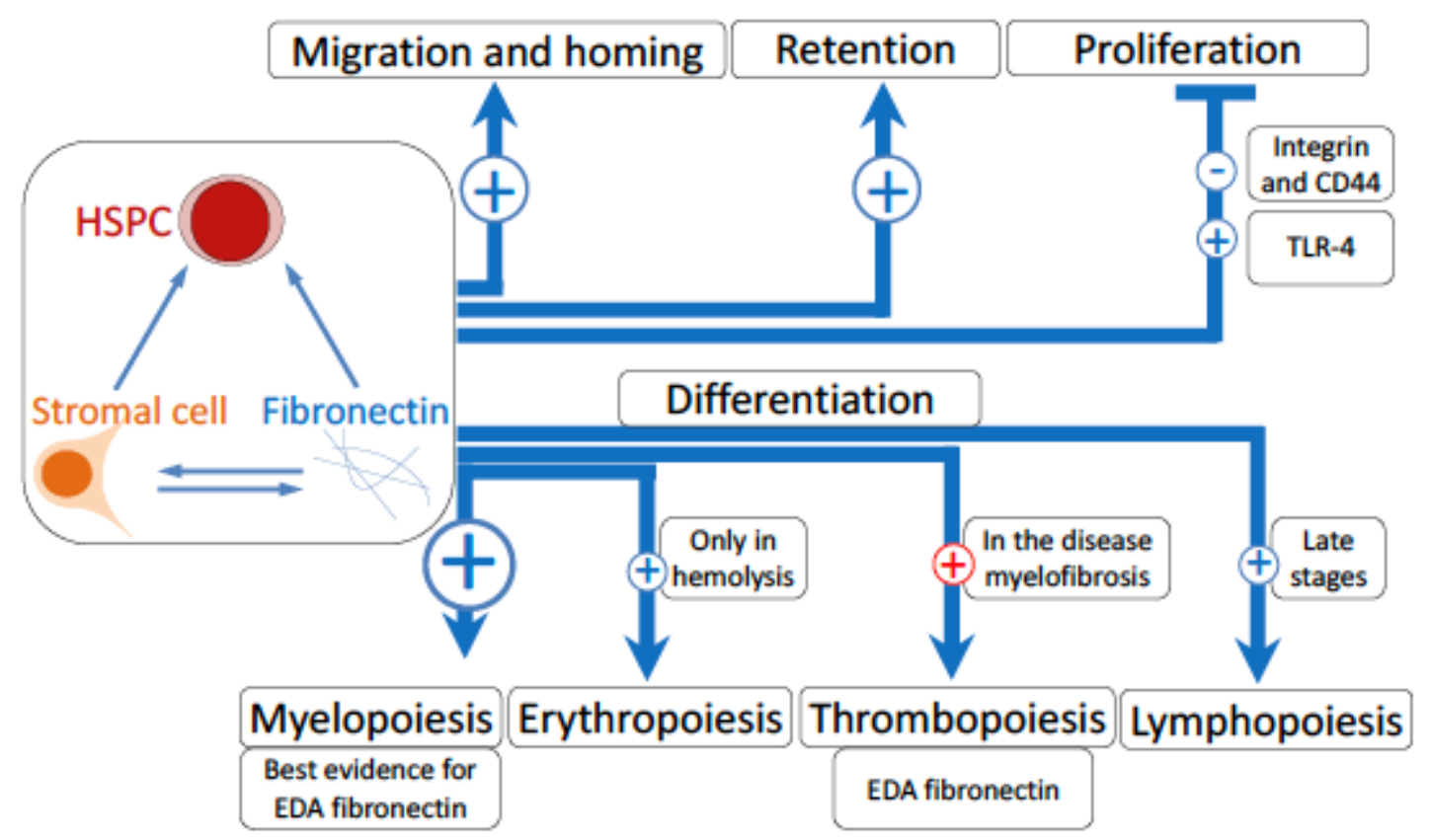

Figure 1. Binding to fibronectin and stromal cells supports various functions of the hematopoietic stem and progenitor cells (HSPC). Migration and homing, as well as retention are stimulated by fibronectin and/or integrins that bind fibronectin. Even though fibronectin normally stimulates cell proliferation, HSPC proliferation is inhibited when integrins engage with fibronectin. CD44 similarly inhibits proliferation. Once stimulated, the receptor TLR-4 enhances proliferation. The lower three arrows refer to the steps of differentiation. Myelopoiesis is increased by the EDA isoform of fibronectin. Erythropoiesis is only defective when fibronectin-binding integrins are manipulated in hemolytic anemia. Defects in thrombopoiesis are associated with fibronectin accumulation in the bone marrow in the disease called myelofibrosis. Defects in the late stages of lymphoid differentiation are seen in modulations of receptors able to bind fibronectin, but no direct link was established with fibronectin. The size of the circle coincides with the strength of the association with fibronectin. The red circle refers to a pathologic condition.

One more integrin was evaluated, namely, $\alpha v \beta 3$. Maintenance of long-term repopulating capacity of hematopoietic stem cells kept in culture or in vivo was found to be dependent on activation with thrombopoietin followed by $\alpha v \beta 3$ [25]. While activation of $\beta 3$ integrin was accomplished using vitronectin, because $\alpha v \beta 3$ is an integrin for vitronectin, fibronectin is also able to bind to $\alpha v \beta 3$, especially when the EDB domain is present [32]. Since osteoblasts produce EDB fibronectin, it is possible that this isoform originating from osteoblasts supports the maintenance of hematopoietic stem cells [12]. This has not been evaluated yet, however.

Taken together, these data suggest that fibronectin at least contributes to retaining the hematopoietic stem cells in their niche either directly by acting on $\alpha v \beta 3$ or indirectly by acting on the supporting stromal cells.

\subsection{Proliferation}

Fibronectin usually stimulates cell proliferation [9]. In the absence of $\alpha \mathrm{v}$ in hematopoietic cells (using Vav-iCre to delete $\alpha \mathrm{v}$ in floxed mice) or periostin, the proliferation of hematopoietic stem cells increased, suggesting that $\alpha \mathrm{v}$ engagement suppresses stem cell proliferation as is the case with $\alpha 4 \beta 1$ [59]. Signaling through $\beta 3$ was found to maintain the long-term repopulation ability of stem cells in vivo [25]. Of note is that $\alpha \mathrm{v} \beta 3$ integrin requires several players that act in concert to 
modulate hematopoietic stem cells. Thrombopoietin, which binds to $\alpha v \beta 3$, sets the stage via inside-out signaling to allow integrin binding to the extracellular matrix. This raises the possibility that fibronectin interaction with $\alpha v \beta 3$ integrin affects proliferation indirectly.

As mentioned, TLR-4 is expressed in hematopoietic stem cells [26,27]. It can bind EDA-fibronectin and the domain III- $1[35,36]$ and is activated by surface molecules on bacteria. Thus, TLR-4 mediates an immune response against bacterial pathogens by enhancing the formation of myeloid cells, and hence, myelopoiesis in the case of infections [65]. This effect seems to be at least in part, indirect originating from cells other than the hematopoietic stem cells $[66,67]$. The activation of TLR-4 on hematopoietic stem cells increases proliferation [60], diminishes self-renewal, while inducing differentiation towards myelopoiesis [27]. In its absence, hematopoietic stem cell expansion is reduced, and the repopulating capacity is improved [68]. Since EDA-fibronectin stimulates TLR-4 signaling [69], it seems reasonable to assume that EDA-fibronectin affects hematopoiesis by enhancing proliferation.

Lastly, CD44 not only supports homing, but also negatively regulates proliferation [28].

\subsection{Differentiation}

The differentiation of hematopoietic stem cells is tightly regulated, leading to the production of the various cell types as needed by the organism. If a person bleeds, erythropoiesis is stimulated. Similarly, infections are associated with an increase in white blood cells that is partially due to an increase in the production of the needed cells in the bone marrow [70]. Our understanding of the mechanisms regulating how and why a hematopoietic stem cell moves along a certain differentiation path remains incomplete.

The role of fibronectin has been evaluated for myelopoiesis and thrombopoiesis. For the remaining hematopoietic steps, we will discuss the receptors that can bind to fibronectin, and at the same time, were studied in hematopoiesis (Table 3).

Table 3. Fibronectin supports myelopoiesis and contributes to pathologic thrombopoiesis (in myelofibrosis). It exerts a limited role in erythropoiesis or lymphopoiesis.

\begin{tabular}{|c|c|c|}
\hline Differentiation Step & Role of Fibronectin & Role of Fibronectin Receptors \\
\hline \multirow{5}{*}{ Myelopoiesis } & \multirow{5}{*}{$\begin{array}{l}\text { EDA fibronectin stimulates } \\
\text { myelopoiesis and changes the immune } \\
\text { response towards cancer [19] }\end{array}$} & $\begin{array}{l}\text { CML is associated with abnormal adhesion to } \alpha 4 \beta 1 \\
\text { and } \alpha 5 \beta 1 \text { [71] }\end{array}$ \\
\hline & & $\alpha 4$ deletion leads to inefficient myelopoiesis $[52,72]$ \\
\hline & & $\begin{array}{c}\alpha 5, \alpha \mathrm{v}, \beta 1 \text {, and } \beta 7 \text { deletion do not affect } \\
\text { myelopoiesis }[23,72]\end{array}$ \\
\hline & & TLR- 4 boosts myelopoiesis $[66,70,73,74]$ \\
\hline & & $\begin{array}{l}\text { CD44 knockout increases monocytes in the bone } \\
\text { marrow and circulation [28] }\end{array}$ \\
\hline \multirow[b]{2}{*}{ Erythropoiesis } & \multirow{2}{*}{$\begin{array}{l}\text { Fibronectin stimulates erythropoiesis } \\
\text { in vitro }[75,76]\end{array}$} & $\alpha 5$ deletion did not affect erythropoiesis [77] \\
\hline & & $\begin{array}{c}\alpha 4 \text { deletion or combined } \beta 1 \text { and } \beta 7 \text { deletion } \\
\text { showed limited recovery after hemolysis }[23,55]\end{array}$ \\
\hline \multirow[b]{2}{*}{ Thrombopoiesis } & \multirow{2}{*}{$\begin{array}{l}\text { In myelofibrosis, fibronectin contributes } \\
\text { to the disease directly, by binding to } \\
\alpha 5 \beta 1 \text { with the possible involvement of } \\
\text { stored molecules }[15,69,78-81]\end{array}$} & $\begin{array}{l}\alpha 4, \beta 1 \text {, and } \beta 7 \text { deletion did not affect } \\
\text { thrombopoiesis }[23,52]\end{array}$ \\
\hline & & $\begin{array}{l}\alpha 4 \text { deletion in hematopoietic and stromal cells } \\
\text { simultaneously prevented the expected increase } \\
\text { after hemolysis }[55,82]\end{array}$ \\
\hline \multirow{5}{*}{ Lymphopoiesis } & & $\alpha 4$ is required for postnatal lymphopoiesis [83] \\
\hline & & $\begin{array}{l}\beta 1 \text { is required for T-cell dependent IgM response to } \\
\text { immunization [64] }\end{array}$ \\
\hline & & TLR-4 affects B- and T-cell maturation [84] \\
\hline & & CD44 deletion increases B-lymphocytes [28] \\
\hline & & Syndecan-4 modulates chemotaxis [43] \\
\hline
\end{tabular}




\subsubsection{Myelopoiesis}

EDA-fibronectin increases myeloid differentiation of hematopoietic stem cells by binding to $\alpha 5 \beta 1$ integrin. This engagement modifies the response of the myeloid cell to cancer. As part of the study of the role of the osteoblastic niche in hematopoiesis, deletion of fibronectin in differentiating osteoblasts showed that myeloid cells of the bone marrow that differentiated in the absence of EDA were able to diminish cancer growth [19]. While the osteoblastic niche is thought of as consisting of bone lining cells, the collagen promoter used to drive Cre expression, and deletion of fibronectin in this model is only effective in differentiating osteoblasts [11]. This suggests that osteoblasts at various stages can modulate hematopoiesis. Since the addition of EDA-fibronectin enhanced myeloid differentiation, it appears that the niche can change hematopoietic cell behavior through the production of different components of the extracellular matrix.

The importance of which receptor is bound to fibronectin is highlighted by the disease of chronic myelogenous leukemia (CML). In this condition, an increase in dysfunctional myeloid cells is seen. Distorted adhesion by $\alpha 4 \beta 1$ and $\alpha 5 \beta 1$, increased survival of myeloid progenitors, and absence of adhesion to stromal cells leads to the uncontrolled increase in myeloid cells and disease manifestation [71]. Of note, however, is that physiologic myelopoiesis proceeds inefficiently in the absence of $\alpha 4$, but is not affected by the absence of $\alpha 5$ or $\alpha v$ [52,72]. The same is true for the deletion of $\beta 1$ and $\beta 7$ integrin subunits [23].

Bacteria, a major source of infections, can activate Toll-like receptors, including TLR-4, which is expressed on hematopoietic stem cells. This leads to the marked production of various cytokines pushing hematopoiesis towards the production of myeloid cells $[66,70,73,74]$. EDA or type III-1 domains in fibronectin were shown to bind to TLR-4, and hence, stimulation of TLR- 4 by fibronectin would presumably be associated with an increase in myelopoiesis [36].

Finally, deletion of CD44, another fibronectin-binding receptor, increases monocytes in the bone marrow and peripheral blood, suggesting it is involved in regulating their differentiation [28].

\subsubsection{Erythropoiesis}

In vitro experiments suggest that fibronectin modulates erythropoiesis [75,76], and induces apoptosis in hematopoietic malignancy [85]. In vivo studies produced complementary results. Combined $\beta 1$ and $\beta 7$ deletion in hematopoietic cells in chimeric mice showed limited recovery after induced hemolytic anemia [23]. In adult mice, deletion of $\alpha 4$ using the Mx promoter, which drives Cre expression in hematopoietic and non-hematopoietic cells, failed to show a difference in erythroid cells $($ Ter119+ $)$ in the bone marrow. After inducing acute hemolytic anemia, however, fewer reticulocytes and lower numbers of red blood cells were detected, suggesting a defect in erythropoiesis under stress [55]. Thus, $\alpha 4 \beta 1$ and/or $\alpha 4 \beta 7$ improve erythropoiesis after hemolysis.

Another set of experiments in vivo is also insightful. Deletion of integrins in erythroid cells using mice expressing the erythropoietin-receptor driving Cre expression in $\alpha 4$ or $\alpha 5$ floxed mice showed that $\alpha 5$ was not required for normal erythropoiesis, because even after stress, the mice lacking $\alpha 5$ in erythroid cells were similar to controls [77]. Deletion of $\alpha 4$ in erythrocytes both early or late during erythroid differentiation led to the retention of erythroblasts in the bone marrow and hampered the last steps in erythrocyte differentiation.

Taken together, in vivo data show no effect of $\alpha 5 \beta 1$ on erythropoiesis. $\alpha 4$, on the other hand, is required under stress conditions. The contribution of fibronectin-binding was not evaluated, however.

\subsubsection{Thrombopoiesis}

In vitro, the role of fibronectin on thrombopoiesis was evaluated. While the engagement of $\alpha 4 \beta 1$ with fibronectin enhanced megakaryopoiesis, $\alpha 5 \beta 1$ seemed less relevant [86]. Even though in vivo studies deleting $\beta 1$ or $\beta 7$ in the bone marrow [23] or complete knockout of $\alpha 4$ [52] failed to show an effect on thrombopoiesis, deletion of $\alpha 4$ using Mx-Cre floxed $\alpha 4$, mice and induction 
of hemolytic stress showed an abnormal response. In normal mice, hemolytic anemia leads to an increase in thrombocytes, because the megakaryocyte-erythrocyte progenitors (MEPs) are shared between erythrocytes and thrombocytes, and hemolysis stimulates erythropoiesis. In Mx-Cre floxed $\alpha 4$ mice, thrombocytes did not increase after hemolytic stress. It is, therefore, conceivable that $\alpha 4$ is involved in these early steps of thrombopoiesis in response to stress [55]. Another possible explanation is that $\alpha 4 \beta 1$ expression in stromal cells modulates thrombopoiesis, because in conditions of severe thrombocytopenia, stromal cells produce more thrombopoietin to increase platelet formation [82]. Since Mx-Cre is active in stromal cells, the inability to increase thrombocytes could result from a defect in the stromal cells in the absence of $\alpha 4$.

Fibronectin was implicated in a disease called primary myelofibrosis. This condition is characterized by the accumulation of extracellular matrix in the bone marrow leading to disruption of hematopoiesis, eventually resulting in anemia, thrombocytosis with defective function, leukopenia, and death. Up to $20 \%$ of patients develop leukemia [87]. In myelofibrosis, not only is the hematopoietic stem cell defective [87], but mesenchymal stromal cells are also abnormal [88,89]. Fibronectin itself modifies the severity of this disease. Therefore, the experimentally-induced disease is more severe in the presence of EDA-fibronectin [69]. Furthermore, lysyl oxidase and TGF- $\beta$, both of which are bound in the matrix in the presence of fibronectin have been implicated in modulating disease severity [15,79-81]. Of note, $\alpha 5 \beta 1$ integrin interaction with fibronectin mediates the increase in megakaryocytes in an experimental model of myelofibrosis, and counteracting this engagement using an inhibitory antibody against $\alpha 5 \beta 1$ diminished the number of megakaryocytes. Taken together, this suggests that the interaction between fibronectin and $\alpha 5 \beta 1$, at least in pathologic conditions, plays a role in thrombopoiesis [78].

\subsubsection{Lymphopoiesis}

Characterization of $\alpha 4$-deficient chimeric mice showed that $\alpha 4$ integrins are not required during fetal life, but are essential for postnatal lymphoid development in the bone marrow [83]. Similarly, $\beta 1$ integrin was not required for hematopoiesis, but immunization failed to induce IgM production, suggesting that $\beta 1$ is required for primary T-cell dependent IgM production [64].

Common lymphoid progenitors (CLPs) not only give rise to lymphocytes, but can also differentiate to become dendritic cells once TLRs are activated [84]. This was shown for activation of TLR-9, which normally is an intracellular receptor. However, TLR-9, similarly to TLR-4, signals through myeloid differentiation factor 88 (MyD88) leading to activation of nuclear factor- $\mathrm{kB}$ (NF- $\mathrm{kB}$ ) [90]. For this reason, the involvement of TLR-4 cannot be excluded. Consequently, EDA-fibronectin might also stimulate the differentiation of CLPs. It should be noted for completeness that TLR4 can use a second signaling pathway to activate NF- $\mathrm{KB}$ by using the so-called TIR domain-containing adaptor-inducing interferon- $\beta$ (TRIF) [90], and there is indirect evidence of the involvement of TLR-4 in lymphopoiesis. This could be merely a change in the relationship of progenitors: Whenever myelopoiesis increases in response to EDA fibronectin, for example, there might be a shift away from lymphopoiesis leading to diminished lymphopoiesis relative to the total number of progenitor cells. This inverse relationship can also result from more fundamental cellular mechanisms, such as a change in transcription factors as suggested by the increase in myelopoiesis and decrease in lymphopoiesis in response to upregulation of microRNA 146a [91]. The role of TLRs is, however, most pronounced in later steps of B-cell differentiation, as well as T-cell differentiation in adaptive immunity, where a role for the EDA domain to enhance lymphocytic responses was proposed [92-94].

CD44 deletion was associated with an increased proportion of B-cells (and monocytes) in the bone marrow and in peripheral blood, suggesting a possible role in regulating their differentiation [28]. Syndecan-4 is expressed on lymphocytes and monocytes and is involved in chemotaxis and immune cell behavior, but no role in modulating hematopoiesis was elicited yet [43]. 


\section{Fibronectin and Malignancy}

In malignancy, the expression of fibronectin is associated with a poor prognosis [9]. Indeed, it seems to be part of the premetastatic niche [95]. This is not the case in hematopoietic malignancies. The binding of malignant hematopoietic cells through syndecan- 4 to tenascin-C and $\alpha 4 \beta 1$ to fibronectin led to their apoptosis. Normal hematopoietic cells, on the other hand, were resistant to syndecan-4 mediated apoptosis, despite the abundance of fibronectin around the normal hematopoietic cells. The authors attributed this to poor expression of syndecan- 4 on normal hematopoietic cells, which might explain the absence of defects in hematopoiesis under normal conditions in syndecan-4 knockout mice [85]. Macrophages, however, express the receptor in amounts that are enough to change their cytokine production in response to lipopolysaccharide [42].

\section{Discussion and Concluding Remarks}

The interaction between the hematopoietic stem- and progenitor cells and their niche is multifaceted. Stromal cells of various origins and extracellular matrix components modulate hematopoiesis by affecting migration and homing, attachment and retention, proliferation, as well as differentiation of the stem cells $[2,19,59]$.

One molecule of particular importance is fibronectin, because it is ubiquitous, is relatively large, and consists of various domains that form diverse isoforms [16]. Fibronectin, by binding several different receptors present on the hematopoietic stem cells or the stromal cells, exerts effects that range from modulating homing of stem cells to the last steps of differentiation of immune cell subsets (Figure 1). Indeed, at least in the case of engraftment of stem cells, preculture in the presence of fibronectin can fully replace the supporting ability of stromal cells, highlighting its importance [50].

Even though fibronectin modulates stem cell behavior in vitro, it is better to rely on in vivo data for any conclusions. How fibronectin might affect hematopoietic stem cells in vivo is difficult to address, however, because a total knockout is lethal prenatally, and fibronectin is expressed by almost all cells in the bone marrow, making it available from other sources whenever one source is excluded. Furthermore, whatever the effect of its deletion in specific cell types is, it needs to be pronounced to be detected [19]. Based on the data obtained manipulating fibronectin-binding receptors in vivo, it seems reasonable to conclude that fibronectin, by acting on $\alpha 4 \beta 1$ and/or $\alpha 5 \beta 1$ on stem cells or on stromal cells, support homing of stem cells to the bone marrow and support retention in the niche, while $\alpha \mathrm{v} \beta 3$ diminishes proliferation $[21,23,25,54,55,59,64]$.

Direct evidence of the effect of fibronectin on the differentiation of hematopoietic cells is available. EDA-fibronectin originating from the osteoblasts engages the classical fibronectin receptor $\alpha 5 \beta 1$ (in a manner that differs from plasma fibronectin lacking EDA) to stimulate myelopoiesis and modulate the immune response towards cancer [19]. These changes were not detected when $\alpha 5$ or $\beta 1$ were deleted in vivo because the change in myelopoiesis is limited in size, and the change in the immune response was not evaluated. Only a small effect of deletion of $\alpha 4$ was also seen [23,72].

The same holds true for thrombopoiesis and erythropoiesis. Fibronectin exerts a limited effect on thrombocyte formation in physiologic conditions by acting through $\alpha 4$ on the stromal cells [55]. In myelofibrosis, EDA-fibronectin contributes to disease progression by acting on $\alpha 5 \beta 1$ [78]. In the case of erythropoiesis, fibronectin stimulation of erythropoiesis only becomes apparent under stress conditions, such as is the case after hemolysis because $\alpha 4 \beta 1$ and/or $\alpha 4 \beta 7$ are involved [55]. Lymphopoiesis seems unrelated to fibronectin. However, $\alpha 4 \beta 1$ is required for later steps of differentiation [64].

The other two potentially relevant fibronectin-binding receptors are CD44, which might facilitate homing and retention, and suppress proliferation [28], as well as TLR-4, which increases stem cell proliferation, their differentiation to myeloid cells, and affects late stages of T- and B-lymphopoiesis $[27,60,68,92,93]$.

Depending on the situation, fibronectin or one of its isoforms might bind another set of receptors. It is possible that during infections, the EDA isoform binds preferably to the hematopoietic stem cell 
TLR- 4 to induce their proliferation and then acts on both $\alpha 5 \beta 1$ and TLR- 4 to stimulate myelopoiesis. This example highlights the complexity of evaluating hematopoiesis. Indeed, the ubiquitous presence of fibronectin in the bone marrow, together with the wide range of effects it and its isoforms can exert, should be taken into account whenever hematopoiesis is evaluated.

The study of fibronectin's role in hematopoiesis has been fraught with obstacles, and evaluating the role of fibronectin in the hematopoietic stem cells, lymphopoiesis, and erythropoiesis in vivo is still missing. This is partly due to the large number of cells that produce fibronectin or its isoforms, or compensation in the amount of fibronectin or in the expression of fibronectin receptors with various manipulations [96]. Furthermore, circulating fibronectin can infiltrate various tissues and modulate the local production of fibronectin [9]. Since the complete knockout dies during embryonal development, work focused on using various transgenic models. The availability of mice that do not express the EDA or the EDB isoform has been helpful in evaluating various biological processes [97]. Animals with constitutive expression of the EDA domain were found to support bone marrow fibrosis development compared to mice that fail to produce any EDA-containing fibronectin [69]. With the use of the Cre-loxP system to delete fibronectin in defined cell populations, it was possible to characterize the role of fibronectin originating from osteoblasts in myeloid cell differentiation [19]. More of such exciting findings are expected as the constituents of the hematopoietic stem cell niche are being characterized, allowing specific deletion of fibronectin in these cell populations.

Because of the critical role of hematopoiesis for survival, it would have been naïve to expect that deletion of a single molecule would throw hematopoiesis off their tracks. Instead, the system is designed such that the loss of one molecule can be compensated for with several mechanisms cooperating for an optimal response of hematopoiesis to the various challenges. Many questions still need to be answered and will keep those evaluating the role of extracellular matrix in hematopoiesis busy for years to come.

Author Contributions: Reviewed the content and made the figure (F.W., A.L., S.H.); wrote the manuscript (I.A.N.). All authors have read and agreed to the published version of the manuscript.

Funding: This research was funded by German Research Council (DFG: NA400/5; NA400/7; NA400/9; NA400/10), Max-Planck Society (M.KF.A.BIOC0001).

Conflicts of Interest: The authors declare no conflict of interest. The funders had no role in the design of the study; in the collection, analyses, or interpretation of data; in the writing of the manuscript, or in the decision to publish the results.

\section{References}

1. Calvi, L.M.; Adams, G.B.; Weibrecht, K.W.; Weber, J.M.; Olson, D.P.; Knight, M.C.; Martin, R.P.; Schipani, E.; Divieti, P.; Bringhurst, F.R.; et al. Osteoblastic cells regulate the haematopoietic stem cell niche. Nature 2003, 425, 841-846. [CrossRef]

2. Szade, K.; Gulati, G.S.; Chan, C.K.F.; Kao, K.S.; Miyanishi, M.; Marjon, K.D.; Sinha, R.; George, B.M.; Chen, J.Y.; Weissman, I.L. Where Hematopoietic Stem Cells Live: The Bone Marrow Niche. Antioxid. Redox Signal. 2018, 29, 191-204. [CrossRef]

3. Ding, L.; Morrison, S.J. Haematopoietic stem cells and early lymphoid progenitors occupy distinct bone marrow niches. Nature 2013, 495, 231-235. [CrossRef]

4. Dallas, S.L.; Sivakumar, P.; Jones, C.J.; Chen, Q.; Peters, D.M.; Mosher, D.F.; Humphries, M.J.; Kielty, C.M. Fibronectin regulates latent transforming growth factor-beta (TGF beta) by controlling matrix assembly of latent TGF beta-binding protein-1. J. Biol. Chem. 2005, 280, 18871-18880. [CrossRef]

5. Granito, R.N.; Bouleftour, W.; Sabido, O.; Lescale, C.; Thomas, M.; Aubin, J.E.; Goodhardt, M.; Vico, L.; Malaval, L. Absence of bone sialoprotein (BSP) alters profoundly hematopoiesis and upregulates osteopontin. J. Cell. Physiol. 2015, 230, 1342-1351. [CrossRef]

6. Cao, H.; Cao, B.; Heazlewood, C.K.; Domingues, M.; Sun, X.; Debele, E.; McGregor, N.E.; Sims, N.A.; Heazlewood, S.Y.; Nilsson, S.K. Osteopontin is an important regulative component of the fetal bone marrow hematopoietic stem cell niche. Cells 2019, 8, 985. [CrossRef] 
7. Siewe, B.T.; Kalis, S.L.; Le, P.T.; Witte, P.L.; Choi, S.; Conway, S.J.; Druschitz, L.; Knight, K.L. In vitro requirement for periostin in B lymphopoiesis. Blood 2011, 117, 3770-3779. [CrossRef]

8. Turner, C.J.; Badu-Nkansah, K.; Hynes, R.O. Endothelium-derived fibronectin regulates neonatal vascular morphogenesis in an autocrine fashion. Angiogenesis 2017, 20, 519-531. [CrossRef]

9. Von Au, A.; Vasel, M.; Kraft, S.; Sens, C.; Hackl, N.; Marx, A.; Stroebel, P.; Hennenlotter, J.; Todenhofer, T.; Stenzl, A.; et al. Circulating fibronectin controls tumor growth. Neoplasia 2013, 15, 925-938. [CrossRef]

10. Zobel, K.; Hansen, U.; Galla, H.J. Blood-brain barrier properties in vitro depend on composition and assembly of endogenous extracellular matrices. Cell Tissue Res. 2016, 365, 233-245. [CrossRef]

11. Bentmann, A.; Kawelke, N.; Moss, D.; Zentgraf, H.; Bala, Y.; Berger, I.; Gasser, J.A.; Nakchbandi, I.A. Circulating fibronectin affects bone matrix, whereas osteoblast fibronectin modulates osteoblast function. J. Bone Min. Res. 2010, 25, 706-715.

12. Sens, C.; Huck, K.; Pettera, S.; Uebel, S.; Wabnitz, G.; Moser, M.; Nakchbandi, I.A. Fibronectins containing extradomain A or B enhance osteoblast differentiation via distinct integrins. J. Biol. Chem. 2017, 292, 7745-7760. [CrossRef]

13. Rossnagl, S.; Ghura, H.; Groth, C.; Altrock, E.; Jakob, F.; Schott, S.; Wimberger, P.; Link, T.; Kuhlmann, J.D.; Stenzl, A.; et al. A subpopulation of stromal cells controls cancer cell homing to the bone marrow. Cancer Res. 2018, 78, 129-142. [CrossRef]

14. Kawelke, N.; Bentmann, A.; Hackl, N.; Hager, H.D.; Feick, P.; Geursen, A.; Singer, M.V.; Nakchbandi, I.A. Isoform of fibronectin mediates bone loss in patients with primary biliary cirrhosis by suppressing bone formation. J. Bone Min. Res. 2008, 23, 1278-1286. [CrossRef]

15. Kawelke, N.; Vasel, M.; Sens, C.; von Au, A.; Dooley, S.; Nakchbandi, I.A. Fibronectin protects from excessive liver fibrosis by modulating the availability of and responsiveness of stellate cells to active TGF-beta. PLOS ONE 2011, 6, e28181. [CrossRef]

16. Leiss, M.; Beckmann, K.; Giros, A.; Costell, M.; Fassler, R. The role of integrin binding sites in fibronectin matrix assembly in vivo. Curr. Opin. Cell Biol. 2008, 20, 502-507. [CrossRef]

17. Sens, C.; Altrock, E.; Rau, K.; Klemis, V.; von Au, A.; Pettera, S.; Uebel, S.; Damm, T.; Tiwari, S.; Moser, M.; et al. An O-glycosylation of fibronectin mediates hepatic osteodystrophy through alpha4beta1 integrin. J. Bone Min. Res. 2017, 32, 70-81. [CrossRef]

18. George, E.L.; Georges-Labouesse, E.N.; Patel-King, R.S.; Rayburn, H.; Hynes, R.O. Defects in mesoderm, neural tube and vascular development in mouse embryos lacking fibronectin. Development 1993, 119, 1079-1091.

19. Rossnagl, S.; Altrock, E.; Sens, C.; Kraft, S.; Rau, K.; Milsom, M.D.; Giese, T.; Samstag, Y.; Nakchbandi, I.A. EDA-fibronectin originating from osteoblasts inhibits the immune response against cancer. PLoS Biol. 2016, 14 , e1002562.

20. Harburger, D.S.; Calderwood, D.A. Integrin signalling at a glance. J. Cell Sci. 2009, 122, 159-163. [CrossRef]

21. Wierenga, P.K.; Weersing, E.; Dontje, B.; de Haan, G.; van Os, R. Differential role for very late antigen-5 in mobilization and homing of hematopoietic stem cells. Bone Marrow Transpl. 2006, 38, 789-797. [CrossRef] [PubMed]

22. Grassinger, J.; Haylock, D.N.; Storan, M.J.; Haines, G.O.; Williams, B.; Whitty, G.A.; Vinson, A.R.; Be, C.L.; Li, S.; Sorensen, E.S.; et al. Thrombin-cleaved osteopontin regulates hemopoietic stem and progenitor cell functions through interactions with alpha9beta1 and alpha4beta1 integrins. Blood 2009, 114, 49-59. [CrossRef]

23. Bungartz, G.; Stiller, S.; Bauer, M.; Muller, W.; Schippers, A.; Wagner, N.; Fassler, R.; Brakebusch, C. Adult murine hematopoiesis can proceed without beta1 and beta7 integrins. Blood 2006, 108, 1857-1864. [CrossRef] [PubMed]

24. Schreiber, T.D.; Steinl, C.; Essl, M.; Abele, H.; Geiger, K.; Muller, C.A.; Aicher, W.K.; Klein, G. The integrin alpha9beta1 on hematopoietic stem and progenitor cells: Involvement in cell adhesion, proliferation and differentiation. Haematologica 2009, 94, 1493-1501. [CrossRef] [PubMed]

25. Umemoto, T.; Yamato, M.; Ishihara, J.; Shiratsuchi, Y.; Utsumi, M.; Morita, Y.; Tsukui, H.; Terasawa, M.; Shibata, T.; Nishida, K.; et al. Integrin-alphavbeta3 regulates thrombopoietin-mediated maintenance of hematopoietic stem cells. Blood 2012, 119, 83-94. [CrossRef] [PubMed]

26. Nagai, Y.; Garrett, K.P.; Ohta, S.; Bahrun, U.; Kouro, T.; Akira, S.; Takatsu, K.; Kincade, P.W. Toll-like receptors on hematopoietic progenitor cells stimulate innate immune system replenishment. Immunity 2006, 24, 801-812. [CrossRef] [PubMed] 
27. Esplin, B.L.; Shimazu, T.; Welner, R.S.; Garrett, K.P.; Nie, L.; Zhang, Q.; Humphrey, M.B.; Yang, Q.; Borghesi, L.A.; Kincade, P.W. Chronic exposure to a TLR ligand injures hematopoietic stem cells. J. Immunol. 2011, 186, 5367-5375. [CrossRef]

28. Cao, H.; Heazlewood, S.Y.; Williams, B.; Cardozo, D.; Nigro, J.; Oteiza, A.; Nilsson, S.K. The role of CD44 in fetal and adult hematopoietic stem cell regulation. Haematologica 2016, 101, 26-37. [CrossRef]

29. Manabe, R.; Ohe, N.; Maeda, T.; Fukuda, T.; Sekiguchi, K. Modulation of cell-adhesive activity of fibronectin by the alternatively spliced EDA segment. J. Cell Biol. 1997, 139, 295-307. [CrossRef]

30. Liao, Y.F.; Gotwals, P.J.; Koteliansky, V.E.; Sheppard, D.; Van De Water, L. The EIIIA segment of fibronectin is a ligand for integrins alpha 9beta 1 and alpha 4 beta 1 providing a novel mechanism for regulating cell adhesion by alternative splicing. J. Biol. Chem. 2002, 277, 14467-14474. [CrossRef]

31. Shinde, A.V.; Bystroff, C.; Wang, C.; Vogelezang, M.G.; Vincent, P.A.; Hynes, R.O.; Van De Water, L. Identification of the peptide sequences within the EIIIA (EDA) segment of fibronectin that mediate integrin alpha9beta1-dependent cellular activities. J. Biol. Chem. 2008, 283, 2858-2870. [CrossRef] [PubMed]

32. Kraft, S.; Klemis, V.; Sens, C.; Lenhard, T.; Jacobi, C.; Samstag, Y.; Wabnitz, G.; Kirschfink, M.; Wallich, R.; Hansch, G.M.; et al. Identification and characterization of a unique role for EDB fibronectin in phagocytosis. J. Mol. Med. 2016, 94, 567-581. [CrossRef]

33. Adair, B.D.; Xiong, J.P.; Maddock, C.; Goodman, S.L.; Arnaout, M.A.; Yeager, M. Three-dimensional EM structure of the ectodomain of integrin \{alpha\}V\{beta\}3 in a complex with fibronectin. J. Cell Biol. 2005, 168, 1109-1118. [CrossRef] [PubMed]

34. Curnis, F.; Longhi, R.; Crippa, L.; Cattaneo, A.; Dondossola, E.; Bachi, A.; Corti, A. Spontaneous formation of L-isoaspartate and gain of function in fibronectin. J. Biol. Chem. 2006, 281, 36466-36476. [CrossRef] [PubMed]

35. Okamura, Y.; Watari, M.; Jerud, E.S.; Young, D.W.; Ishizaka, S.T.; Rose, J.; Chow, J.C.; Strauss, J.F., 3rd. The extra domain A of fibronectin activates Toll-like receptor 4. J. Biol. Chem. 2001, 276, 10229-10233. [CrossRef]

36. You, R.; Zheng, M.; McKeown-Longo, P.J. The first type III repeat in fibronectin activates an inflammatory pathway in dermal fibroblasts. J. Biol. Chem. 2010, 285, 36255-36259. [CrossRef] [PubMed]

37. Hackl, N.J.; Bersch, C.; Feick, P.; Antoni, C.; Franke, A.; Singer, M.V.; Nakchbandi, I.A. Circulating fibronectin isoforms predict the degree of fibrosis in chronic hepatitis C. Scand. J. Gastroenterol. 2010, 45, 349-356. [CrossRef]

38. Sackstein, R. The biology of CD44 and HCELL in hematopoiesis: The 'step 2-bypass pathway' and other emerging perspectives. Curr. Opin. Hematol. 2011, 18, 239-248. [CrossRef]

39. Verfaillie, C.M.; Benis, A.; Iida, J.; McGlave, P.B.; McCarthy, J.B. Adhesion of committed human hematopoietic progenitors to synthetic peptides from the C-terminal heparin-binding domain of fibronectin: Cooperation between the integrin alpha 4 beta 1 and the CD44 adhesion receptor. Blood 1994, 84, 1802-1811. [CrossRef]

40. Tumova, S.; Woods, A.; Couchman, J.R. Heparan sulfate chains from glypican and syndecans bind the Hep II domain of fibronectin similarly despite minor structural differences. J. Biol. Chem. 2000, 275, 9410-9417. [CrossRef]

41. Morgan, M.R.; Hamidi, H.; Bass, M.D.; Warwood, S.; Ballestrem, C.; Humphries, M.J. Syndecan-4 phosphorylation is a control point for integrin recycling. Dev. Cell 2013, 24, 472-485. [CrossRef] [PubMed]

42. Ishiguro, K.; Kadomatsu, K.; Kojima, T.; Muramatsu, H.; Iwase, M.; Yoshikai, Y.; Yanada, M.; Yamamoto, K.; Matsushita, T.; Nishimura, M.; et al. Syndecan-4 deficiency leads to high mortality of lipopolysaccharide-injected mice. J. Biol. Chem. 2001, 276, 47483-47488. [CrossRef] [PubMed]

43. Kaneider, N.C.; Reinisch, C.M.; Dunzendorfer, S.; Romisch, J.; Wiedermann, C.J. Syndecan-4 mediates antithrombin-induced chemotaxis of human peripheral blood lymphocytes and monocytes. J. Cell Sci. 2002, 115, 227-236.

44. Weissman, I.L. Developmental switches in the immune system. Cell 1994, 76, 207-218. [CrossRef]

45. Bryder, D.; Rossi, D.J.; Weissman, I.L. Hematopoietic stem cells: The paradigmatic tissue-specific stem cell. Am. J. Pathol. 2006, 169, 338-346. [CrossRef]

46. Ruppert, R.; Moser, M.; Sperandio, M.; Rognoni, E.; Orban, M.; Liu, W.H.; Schulz, A.S.; Oostendorp, R.A.; Massberg, S.; Fassler, R. Kindlin-3-mediated integrin adhesion is dispensable for quiescent but essential for activated hematopoietic stem cells. J. Exp. Med. 2015, 212, 1415-1432. [CrossRef]

47. Ma, Q.; Jones, D.; Springer, T.A. The chemokine receptor CXCR4 is required for the retention of B lineage and granulocytic precursors within the bone marrow microenvironment. Immunity 1999, 10, 463-471. [CrossRef] 
48. Broxmeyer, H.E. Regulation of hematopoiesis by chemokine family members. Int. J. Hematol. 2001, 74, 9-17. [CrossRef]

49. Imai, K.; Kobayashi, M.; Wang, J.; Ohiro, Y.; Hamada, J.; Cho, Y.; Imamura, M.; Musashi, M.; Kondo, T.; Hosokawa, M.; et al. Selective transendothelial migration of hematopoietic progenitor cells: A role in homing of progenitor cells. Blood 1999, 93, 149-156.

50. Sagar, B.M.; Rentala, S.; Gopal, P.N.; Sharma, S.; Mukhopadhyay, A. Fibronectin and laminin enhance engraftibility of cultured hematopoietic stem cells. Biochem. Biophys. Res. Commun. 2006, 350, 1000-1005. [CrossRef]

51. Potocnik, A.J.; Brakebusch, C.; Fassler, R. Fetal and adult hematopoietic stem cells require beta1 integrin function for colonizing fetal liver, spleen, and bone marrow. Immunity 2000, 12, 653-663. [CrossRef]

52. Arroyo, A.G.; Yang, J.T.; Rayburn, H.; Hynes, R.O. Alpha4 integrins regulate the proliferation/differentiation balance of multilineage hematopoietic progenitors in vivo. Immunity 1999, 11, 555-566. [CrossRef]

53. Papayannopoulou, T.; Craddock, C.; Nakamoto, B.; Priestley, G.V.; Wolf, N.S. The VLA4/VCAM-1 adhesion pathway defines contrasting mechanisms of lodgement of transplanted murine hemopoietic progenitors between bone marrow and spleen. Proc. Natl. Acad. Sci. USA 1995, 92, 9647-9651. [CrossRef] [PubMed]

54. Katayama, Y.; Hidalgo, A.; Peired, A.; Frenette, P.S. Integrin alpha4beta7 and its counterreceptor MAdCAM-1 contribute to hematopoietic progenitor recruitment into bone marrow following transplantation. Blood 2004, 104, 2020-2026. [CrossRef]

55. Scott, L.M.; Priestley, G.V.; Papayannopoulou, T. Deletion of alpha4 integrins from adult hematopoietic cells reveals roles in homeostasis, regeneration, and homing. Mol. Cell Biol. 2003, 23, 9349-9360. [CrossRef]

56. Sackstein, R.; Merzaban, J.S.; Cain, D.W.; Dagia, N.M.; Spencer, J.A.; Lin, C.P.; Wohlgemuth, R. Ex vivo glycan engineering of CD44 programs human multipotent mesenchymal stromal cell trafficking to bone. Nat. Med. 2008, 14, 181-187. [CrossRef]

57. Cancelas, J.A. Adhesion, migration, and homing of murine hematopoietic stem cells and progenitors. Methods Mol. Biol. 2011, 750, 187-196.

58. Papayannopoulou, T.; Nakamoto, B. Peripheralization of hemopoietic progenitors in primates treated with anti-VLA4 integrin. Proc. Natl. Acad. Sci. USA 1993, 90, 9374-9378. [CrossRef]

59. Khurana, S.; Schouteden, S.; Manesia, J.K.; Santamaria-Martinez, A.; Huelsken, J.; Lacy-Hulbert, A.; Verfaillie, C.M. Outside-in integrin signalling regulates haematopoietic stem cell function via Periostin-Itgav axis. Nat. Commun. 2016, 7, 13500.

60. Liu, A.; Wang, Y.; Ding, Y.; Baez, I.; Payne, K.J.; Borghesi, L. Cutting edge: Hematopoietic stem cell expansion and common lymphoid progenitor depletion require hematopoietic-derived, cell-autonomous TLR4 in a model of chronic endotoxin. J. Immunol. 2015, 195, 2524-2528. [CrossRef]

61. Dao, M.A.; Nolta, J.A. Cytokine and integrin stimulation synergize to promote higher levels of GATA-2, c-myb, and CD34 protein in primary human hematopoietic progenitors from bone marrow. Blood 2007, 109, 2373-2379. [CrossRef]

62. Abbuehl, J.P.; Tatarova, Z.; Held, W.; Huelsken, J. Long-Term Engraftment of Primary Bone Marrow Stromal Cells Repairs Niche Damage and Improves Hematopoietic Stem Cell Transplantation. Cell Stem Cell 2017, 21, 241-255.e6. [CrossRef] [PubMed]

63. Dao, M.A.; Hashino, K.; Kato, I.; Nolta, J.A. Adhesion to fibronectin maintains regenerative capacity during ex vivo culture and transduction of human hematopoietic stem and progenitor cells. Blood 1998, 92, 4612-4621. [CrossRef] [PubMed]

64. Brakebusch, C.; Fillatreau, S.; Potocnik, A.J.; Bungartz, G.; Wilhelm, P.; Svensson, M.; Kearney, P.; Korner, H.; Gray, D.; Fassler, R. Beta1 integrin is not essential for hematopoiesis but is necessary for the T cell-dependent IgM antibody response. Immunity 2002, 16, 465-477. [PubMed]

65. Ziegler, P.; Boettcher, S.; Takizawa, H.; Manz, M.G.; Brummendorf, T.H. LPS-stimulated human bone marrow stroma cells support myeloid cell development and progenitor cell maintenance. Ann. Hematol. 2016, 95, 173-178. [CrossRef] [PubMed]

66. Boettcher, S.; Ziegler, P.; Schmid, M.A.; Takizawa, H.; van Rooijen, N.; Kopf, M.; Heikenwalder, M.; Manz, M.G. Cutting edge: LPS-induced emergency myelopoiesis depends on TLR4-expressing nonhematopoietic cells. J. Immunol. 2012, 188, 5824-5828. [CrossRef] 
67. Boettcher, S.; Gerosa, R.C.; Radpour, R.; Bauer, J.; Ampenberger, F.; Heikenwalder, M.; Kopf, M.; Manz, M.G. Endothelial cells translate pathogen signals into G-CSF-driven emergency granulopoiesis. Blood 2014, 124, 1393-1403. [CrossRef]

68. Schuettpelz, L.G.; Borgerding, J.N.; Christopher, M.J.; Gopalan, P.K.; Romine, M.P.; Herman, A.C.; Woloszynek, J.R.; Greenbaum, A.M.; Link, D.C. G-CSF regulates hematopoietic stem cell activity, in part, through activation of Toll-like receptor signaling. Leukemia 2014, 28, 1851-1860. [CrossRef]

69. Malara, A.; Gruppi, C.; Abbonante, V.; Cattaneo, D.; De Marco, L.; Massa, M.; Iurlo, A.; Gianelli, U.; Balduini, C.L.; Tira, M.E.; et al. EDA fibronectin-TLR4 axis sustains megakaryocyte expansion and inflammation in bone marrow fibrosis. J. Exp. Med. 2019, 216, 587-604. [CrossRef]

70. Pietras, E.M.; Mirantes-Barbeito, C.; Fong, S.; Loeffler, D.; Kovtonyuk, L.V.; Zhang, S.; Lakshminarasimhan, R.; Chin, C.P.; Techner, J.M.; Will, B.; et al. Chronic interleukin-1 exposure drives haematopoietic stem cells towards precocious myeloid differentiation at the expense of self-renewal. Nat. Cell Biol. 2016, 18, 607-618. [CrossRef]

71. Bhatia, R.; Munthe, H.A.; Verfaillie, C.M. Role of abnormal integrin-cytoskeletal interactions in impaired beta1 integrin function in chronic myelogenous leukemia hematopoietic progenitors. Exp. Hematol. 1999, 27, 1384-1396. [CrossRef]

72. Arroyo, A.G.; Taverna, D.; Whittaker, C.A.; Strauch, U.G.; Bader, B.L.; Rayburn, H.; Crowley, D.; Parker, C.M.; Hynes, R.O. In vivo roles of integrins during leukocyte development and traffic: Insights from the analysis of mice chimeric for alpha 5, alpha v, and alpha 4 integrins. J. Immunol. 2000, 165, 4667-4675. [CrossRef]

73. Zhao, J.L.; Ma, C.; O'Connell, R.M.; Mehta, A.; DiLoreto, R.; Heath, J.R.; Baltimore, D. Conversion of danger signals into cytokine signals by hematopoietic stem and progenitor cells for regulation of stress-induced hematopoiesis. Cell Stem Cell 2014, 14, 445-459. [CrossRef]

74. Hernandez, G.; Mills, T.S.; Rabe, J.L.; Chavez, J.S.; Kuldanek, S.; Kirkpatrick, G.; Noetzli, L.; Jubair, W.K.; Zanche, M.; Myers, J.R.; et al. Pro-inflammatory cytokine blockade attenuates myeloid expansion in a murine model of rheumatoid arthritis. Haematologica 2020, 105, 585-597. [CrossRef] [PubMed]

75. Kapur, R.; Cooper, R.; Zhang, L.; Williams, D.A. Cross-talk between alpha(4)beta(1)/alpha(5)beta(1) and c-Kit results in opposing effect on growth and survival of hematopoietic cells via the activation of focal adhesion kinase, mitogen-activated protein kinase, and Akt signaling pathways. Blood 2001, 97, 1975-1981. [CrossRef] [PubMed]

76. $\quad$ Eshghi, S.; Vogelezang, M.G.; Hynes, R.O.; Griffith, L.G.; Lodish, H.F. Alpha4beta1 integrin and erythropoietin mediate temporally distinct steps in erythropoiesis: Integrins in red cell development. J. Cell Biol. 2007, 177, 871-880. [CrossRef] [PubMed]

77. Ulyanova, T.; Padilla, S.M.; Papayannopoulou, T. Stage-specific functional roles of integrins in murine erythropoiesis. Exp. Hematol. 2014, 42, 404-409. [CrossRef]

78. Matsuura, S.; Thompson, C.R.; Ng, S.K.; Ward, C.M.; Karagianni, A.; Mazzeo, C.; Malara, A.; Balduini, A.; Ravid, K. Adhesion to fibronectin via alpha5beta1 integrin supports expansion of the megakaryocyte lineage in primary myelofibrosis. Blood 2020, 135, 2286-2291. [CrossRef]

79. Fogelgren, B.; Polgar, N.; Szauter, K.M.; Ujfaludi, Z.; Laczko, R.; Fong, K.S.; Csiszar, K. Cellular fibronectin binds to lysyl oxidase with high affinity and is critical for its proteolytic activation. J. Biol. Chem. 2005, 280, 24690-24697.

80. Zahr, A.A.; Salama, M.E.; Carreau, N.; Tremblay, D.; Verstovsek, S.; Mesa, R.; Hoffman, R.; Mascarenhas, J. Bone marrow fibrosis in myelofibrosis: Pathogenesis, prognosis and targeted strategies. Haematologica 2016, 101, 660-671. [CrossRef]

81. Kimura, A.; Katoh, O.; Hyodo, H.; Kuramoto, A. Transforming growth factor-beta regulates growth as well as collagen and fibronectin synthesis of human marrow fibroblasts. Br. J. Haematol. 1989, 72, 486-491. [CrossRef] [PubMed]

82. Kaushansky, K. The molecular mechanisms that control thrombopoiesis. J. Clin. Investig. 2005, 115, 3339-3347. [CrossRef] [PubMed]

83. Arroyo, A.G.; Yang, J.T.; Rayburn, H.; Hynes, R.O. Differential requirements for alpha4 integrins during fetal and adult hematopoiesis. Cell 1996, 85, 997-1008. [CrossRef]

84. Welner, R.S.; Pelayo, R.; Nagai, Y.; Garrett, K.P.; Wuest, T.R.; Carr, D.J.; Borghesi, L.A.; Farrar, M.A.; Kincade, P.W. Lymphoid precursors are directed to produce dendritic cells as a result of TLR9 ligation during herpes infection. Blood 2008, 112, 3753-3761. [CrossRef] 
85. Saito, Y.; Owaki, T.; Matsunaga, T.; Saze, M.; Miura, S.; Maeda, M.; Eguchi, M.; Tanaka, R.; Taira, J.; Kodama, H.; et al. Apoptotic death of hematopoietic tumor cells through potentiated and sustained adhesion to fibronectin via VLA-4. J. Biol. Chem. 2010, 285, 7006-7015. [CrossRef]

86. Fox, N.E.; Kaushansky, K. Engagement of integrin alpha4beta1 enhances thrombopoietin-induced megakaryopoiesis. Exp. Hematol. 2005, 33, 94-99. [CrossRef]

87. Tefferi, A. Primary myelofibrosis: 2019 update on diagnosis, risk-stratification and management. Am. J. Hematol. 2018, 93, 1551-1560. [CrossRef]

88. Manshouri, T.; Verstovsek, S.; Harris, D.M.; Veletic, I.; Zhang, X.; Post, S.M.; Bueso-Ramos, C.E.; Estrov, Z. Primary myelofibrosis marrow-derived CD14+/CD34- monocytes induce myelofibrosis-like phenotype in immunodeficient mice and give rise to megakaryocytes. PLoS ONE 2019, 14, e0222912. [CrossRef]

89. Schneider, R.K.; Ziegler, S.; Leisten, I.; Ferreira, M.S.; Schumacher, A.; Rath, B.; Fahrenkamp, D.; Muller-Newen, G.; Crysandt, M.; Wilop, S.; et al. Activated fibronectin-secretory phenotype of mesenchymal stromal cells in pre-fibrotic myeloproliferative neoplasms. J. Hematol. Oncol. 2014, 7, 92. [CrossRef]

90. Lim, K.H.; Staudt, L.M. Toll-like receptor signaling. Cold Spring Harb. Perspect. Biol. 2013, 5, a011247. [CrossRef]

91. Starczynowski, D.T.; Kuchenbauer, F.; Wegrzyn, J.; Rouhi, A.; Petriv, O.; Hansen, C.L.; Humphries, R.K.; Karsan, A. MicroRNA-146a disrupts hematopoietic differentiation and survival. Exp. Hematol. 2011, 39, 167-178.e4. [CrossRef] [PubMed]

92. Hua, Z.; Hou, B. TLR signaling in B-cell development and activation. Cell Mol. Immunol. 2013, 10, $103-106$. [CrossRef] [PubMed]

93. Jin, B.; Sun, T.; Yu, X.H.; Yang, Y.X.; Yeo, A.E. The effects of TLR activation on T-cell development and differentiation. Clin. Dev. Immunol. 2012, 2012, 836485. [CrossRef] [PubMed]

94. San Roman, B.; De Andres, X.; Munoz, P.M.; Obregon, P.; Asensio, A.C.; Garrido, V.; Mansilla, C.; Arribillaga, L.; Lasarte, J.J.; De Andres, D.; et al. The extradomain A of fibronectin (EDA) combined with poly(I:C) enhances the immune response to HIV-1 p24 protein and the protection against recombinant Listeria monocytogenes-Gag infection in the mouse model. Vaccine 2012, 30, 2564-2569. [CrossRef]

95. Kaplan, R.N.; Riba, R.D.; Zacharoulis, S.; Bramley, A.H.; Vincent, L.; Costa, C.; MacDonald, D.D.; Jin, D.K.; Shido, K.; Kerns, S.A.; et al. VEGFR1-positive haematopoietic bone marrow progenitors initiate the pre-metastatic niche. Nature 2005, 438, 820-827. [CrossRef]

96. Malara, A.; Gruppi, C.; Celesti, G.; Romano, B.; Laghi, L.; De Marco, L.; Muro, A.F.; Balduini, A. Brief Report: Alternative Splicing of Extra Domain A (EIIIA) of Fibronectin Plays a Tissue-Specific Role in Hematopoietic Homeostasis. Stem Cells 2016, 34, 2263-2268. [CrossRef]

97. Astrof, S.; Crowley, D.; Hynes, R.O. Multiple cardiovascular defects caused by the absence of alternatively spliced segments of fibronectin. Dev. Biol. 2007, 311, 11-24. [CrossRef]

Publisher's Note: MDPI stays neutral with regard to jurisdictional claims in published maps and institutional affiliations.

(C) 2020 by the authors. Licensee MDPI, Basel, Switzerland. This article is an open access article distributed under the terms and conditions of the Creative Commons Attribution (CC BY) license (http://creativecommons.org/licenses/by/4.0/). 